\title{
Interactions between Phosphorus- and Nitrogen-Containing Flame Retardants
}

\author{
Hajime Nishihara, Susumu TanjI, and Ryuichiro Kanatani \\ Department of Styrenic Resins Development, \\ Asahi Chemical Industry Co., Ltd., \\ Kawasaki, Kanagawa 210, Japan
}

(Received November 29, 1996)

\begin{abstract}
A halogen-free, flame-retardant polystyrene containing polyphenylene ether (PPE) with excellent melt flow, impact resistance, and heat resistance can be obtained through concurrent use of hydroxyphenyl-containing phosphate (resorcinyl diphenyl phosphate: triphenyl phosphate (TPP) $\mathrm{OH}$ ) as phosphorus-containing flame retardant and melamine cyanurate (MC) as nitrogen-containing flame retardant. Investigation of interactions between these two flame retardants showed that an intumescent process, which involves the formation of char that swells and foams, occurs upon the burning of this resin composition and lowers the burning surface temperature by $130^{\circ} \mathrm{C}$ compared with the resin composition without $\mathrm{MC}$, in which the intumescent process does not occur. The resin composition containing TPP $\mathrm{OH} / \mathrm{MC}$ has higher impact resistance than that containing TPP/MC (TPP: contains no hydroxyl group). Viscoelastic measurement indicated significant interactions between TPP-OH and MC, including particularly hydrogen bonding between their hydroxyl and amino groups, which suggests that TPP $\mathrm{OH}$ acts as a compatibilizer of $\mathrm{MC}$.

KEY WORDS Styrenic Resin/Hydroxyphenyl-Containing Phosphate/Resorcinyl Diphenyl Phosphate

Melamine Cyanurate / Burning Surface Temperature / Intumescent /
\end{abstract}

The use of a hydroxyphenyl-containing phosphate, which is a flow modifier as well as flame retardant, provides a halogen-free, flame-retardant polystyrene excellent in flowability, flame retardance, heat resistance, and impact resistance. ${ }^{1-4}$

Phosphorus-containing and nitrogen-containing flame retardants, when used together, exhibit synergistic flame retardation effects. The use of conventional phosphate as the phosphorus-containing flame retardant in this case, however, adversely affects the impact resistance, though it enhances flame retardance, thus making it unsuitable for practical use. It is through the use of a hydroxyphenyl-containing phosphate that the utilization of the above synergistic effects has been made possible, so as to attain an enhanced level of flame retardance combined with excellent flowability and heat resistance without sacrificing impact resistance. ${ }^{5-8}$

This paper describes our work to elucidate the mechanisms of this flame retardance enhancement and impact resistance retention, in terms of interactions between the phosphorus-containing flame retardant and the nitrogen-containing flame retardant.

\section{EXPERIMENTAL}

\section{Materials}

We used a polybutadiene (PB) modified polystyrene (PS) (PS : $\mathrm{PB}=88: 12$ by weight) as high impact polystyrene (HIPS); poly(oxy-2,6-dimethyl-1,4-phenylene) as polyphenylene ether (PPE). These resins are manufactured and sold by Asahi Chemical Industry Co., Ltd., Japan. Triphenyl phosphate (TPP) manufactured by Daihachi Chemical Industry Co., Ltd., Japan, was used as the phosphate containing no hydroxyphenyl group; melamine cyanurate (MC) manufactured by Nissan Chemical Industry Co., Ltd., Japan, was used as the nitrogen-containing flame retardant.

Resorcinyl diphenyl phosphate (TPP-OH) was prepared as follows:
A flask was charged with 122.7 parts of phenol and 0.87 part of aluminum chloride, and 100 parts of phosphorus oxychloride were added dropwise at $90^{\circ} \mathrm{C}$ over $1 \mathrm{~h}$ (phenol: aluminum chloride: phosphorus oxychloride molar ratio $=2.0: 0.01: 1.0$ ). To the intermediate product thus formed were added 71.7 parts (molar ratio: 1.0) of resorcinol to further continue reaction. The reaction mixture was gradually heated to $180^{\circ} \mathrm{C}$ to complete esterification. The reaction product was cooled and washed with water. The catalyst and chlorine were removed to obtain a phosphoric ester mixture (designated FR-1). As a result of gel-permeation chromatography (GPC), the mixture was found to comprise resorcinyl diphenyl phosphate, TPP, and resorcinol bis(diphenyl phosphate) in a ratio of $54.2: 18.3: 27.5$. The mixture (FR-1) was distilled, and then fractionated by GPC to obtain resorcinyl diphenyl phosphate.

GPC measurement conditions: GPC (available from Tosoh Co., Ltd. of Japan; chromatography apparatus (equipped with RI refractive index detector): HLC-8020; column; available from Tosoh Co., Ltd., G1000HXL (2 sets used); mobile phase: tetrahydrofuran; flow rate: $0.8 \mathrm{ml} \mathrm{min}^{-1}$; pressure: $60 \mathrm{kgf} \mathrm{cm}^{-2}$; temperature: $35^{\circ} \mathrm{C}$ (inlet), $40^{\circ} \mathrm{C}$ (oven), $35^{\circ} \mathrm{C}$ (RI); sample loop: $100 \mathrm{ml}$; injected amount of sample: $0.08 \mathrm{~g} / 20 \mathrm{ml}$ ).

TPP-OH was identified by FT-IR spectroscopy and GC-mass spectrometry (MS) as follows:

- FT-IR spectroscopic data $\left(\mathrm{cm}^{-1}\right)$

$v(\mathrm{OH}) \quad 3311.2 \quad v(\mathrm{CH}) 3074.0$

$v(\mathrm{C}-\mathrm{C}) \quad 1600.7,1591.0,1488.8,1457.9$

$v(\mathrm{P}=\mathrm{O}) \quad 1296.0,1274.7$

$v$ (POC) $1186.0,1162.9,1134.0,1072.2$

$\delta(\mathrm{CH}) \quad 1012.5,970.0$

$v(\mathrm{C}=\mathrm{C}) 906.4,773.3$

$\delta(\mathrm{C}-\mathrm{C}) \quad 756.0$

- GC-MS data

$m / z$ 
<smiles>[14CH3]c1cccc(OP(=O)(Oc2ccccc2)Oc2ccccc2)c1</smiles><smiles></smiles>

\section{Preparation of Specimens}

The components of each resin composition shown in the tables herein were mechanically mixed at the compounding ratio indicated, and the mixture was melted in a Laboplastomill batch mixer manufactured by Toyo Seiki Seisakusho. The resulting resin composition was compression molded to prepare specimens.

\section{Measurements}

Izod Impact Strength. Measured in accordance with ASTM D256 at $23^{\circ} \mathrm{C}$, using a V-notched, 1/8-inch-thick specimen.

Heat Resistance (Vicat Softening Temperature). Measured in accordance with ASTM D1525.

Melt Flow Rate $(M F R)$. Determined in accordance with ISO R 1133 by measuring the extrusion rate at $200^{\circ} \mathrm{C}$ under a load of $5 \mathrm{~kg}$ and converting the value obtained into grams per $10 \mathrm{~min}$.

Flame Retardance. Evaluated by a vertical burning (VB) test in accordance with UL-94. A 1/8-inch-thick specimen was used.

Thermogravimetric Analysis (TGA). The resin composition was heated at a rate of $40^{\circ} \mathrm{C} \mathrm{min}{ }^{-1}$ in a stream of nitrogen by means of Type DT-40 thermal analyzer from Shimadzu Corp. of Japan. Carbonous residue at $550^{\circ} \mathrm{C}$ was taken as a measure of char formation.

Average Heat Release Rate. Measured with Cone Calorimeter II from ATLAS Electric Devices Co. of
U.S.A., in accordance with ASTM E1354. The measurement was conducted at a radiant heat flux of $50 \mathrm{~kW} \mathrm{~m}^{-2}$ with the sample placed horizontally. The area of the sample was $0.006 \mathrm{~m}^{2}$.

Burning Surface Temperature. Measured by placing a thermocouple in contact with the burning surface of the specimen.

Viscoelastic Behavior (tan $\delta$ ). Measured with rheometrics mechanical spectrometer. The test was carried out from $-150^{\circ} \mathrm{C}$ to $100^{\circ} \mathrm{C}$ and frequency of $5 \mathrm{~Hz}$.

\section{RESULTS AND DISCUSSION}

\section{Impact Resistance and Interaction between Flame Re- tardants}

Table I shows the effects of MC addition on the flame retardance, MFR, Izod impact strength, and Vicat softening temperature of specimens molded from HIPS/ PPE resin compositions with and without phosphate (TPP-OH or TPP). The addition of MC in the presence of TPP lowers impact strength to a significant degree but the decline is less in the presence of TPP$\mathrm{OH}$ instead of TPP. From this, it may be speculated that the hydroxyl group in TPP-OH exhibits interactions, such as hydrogen bonding, with the amino group in $\mathrm{MC}$ and thereby improves the MC compatibility with and dispersibility in the resin.

Figure 1 shows the viscoelastic behavior of specimens molded from the resin compositions comprising HIPS/ PPE/TPP and HIPS/PPE/TPP-OH shown in Table I, with and without $\mathrm{MC}$ addition. These curves indicate the following: all compositions containing TPP show similar behavior regardless of the presence or absence of $\mathrm{MC}$; in the specimens made from compositions containing TPP-OH, the peak around $-30^{\circ} \mathrm{C}$, derived from TPP-OH, shifts toward higher temperatures when $\mathrm{MC}$ is present. This suggests significant interaction between $\mathrm{TPP}-\mathrm{OH}$ and $\mathrm{MC}$.

Figure 2 shows FT-IR spectroscopic data of specimens from the resin compositions comprising HIPS/PPE/ TPP/MC and HIPS/PPE/TPP-OH/MC shown in Table I.

At $3392 \mathrm{~cm}^{-1}$ of $\mathrm{NH}_{2}$ stretching in $\mathrm{MC}$, the absorbance of the resin composition containing TPP-OH shifts $3 \mathrm{~cm}^{-1}$ to a lower wave number than that of the resin containing TPP and exhibits a broad band.

This suggests significant interactions between TPP $\mathrm{OH}$ and $\mathrm{MC}$, including hydrogen bonding between the hydroxyl and amino group.

Table I. Effects of melamine cyanurate (MC) on resin properties

\begin{tabular}{|c|c|c|c|c|c|c|c|c|}
\hline \multirow{2}{*}{ No. } & \multicolumn{4}{|c|}{$\begin{array}{l}\text { Resin compositon } \\
\quad \text { (weight ratio) }\end{array}$} & \multirow{2}{*}{$\begin{array}{l}\text { Flame } \\
\text { retardance } \\
\text { UL-94 }\end{array}$} & \multirow{2}{*}{$\begin{array}{c}\begin{array}{c}\text { Izod } \\
\text { impact } \\
\text { strength }\end{array} \\
\mathrm{kg} \cdot \mathrm{cm} \mathrm{cm}^{-1}\end{array}$} & \multirow{2}{*}{$\begin{array}{c}\text { MFR } \\
\mathrm{g} / 10 \mathrm{~min}\end{array}$} & \multirow{2}{*}{$\begin{array}{c}\begin{array}{c}\text { Vicat } \\
\text { softening } \\
\text { temp }\end{array} \\
{ }^{\circ} \mathrm{C}\end{array}$} \\
\hline & Resin & \multicolumn{2}{|c|}{ Phosphate } & $\begin{array}{l}\text { Triazine } \\
\text { MC }\end{array}$ & & & & \\
\hline 1 & & 0 & 0 & 0 & $\mathrm{HB}^{\mathrm{a}}$ & 14.4 & 0.4 & 124.4 \\
\hline 2 & HIPS/PPE & 19 & 0 & 0 & V-1 & 14.3 & 5.5 & 102.0 \\
\hline 3 & $=74 / 26$ & 0 & 19 & 0 & V-1 & 14.0 & 8.7 & 84.0 \\
\hline 4 & & 19 & 0 & 8 & V-0 & 11.2 & 5.0 & 102.8 \\
\hline 5 & & 0 & 19 & 8 & V-0 & 7.2 & 8.2 & 84.6 \\
\hline
\end{tabular}

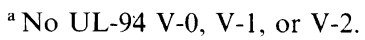




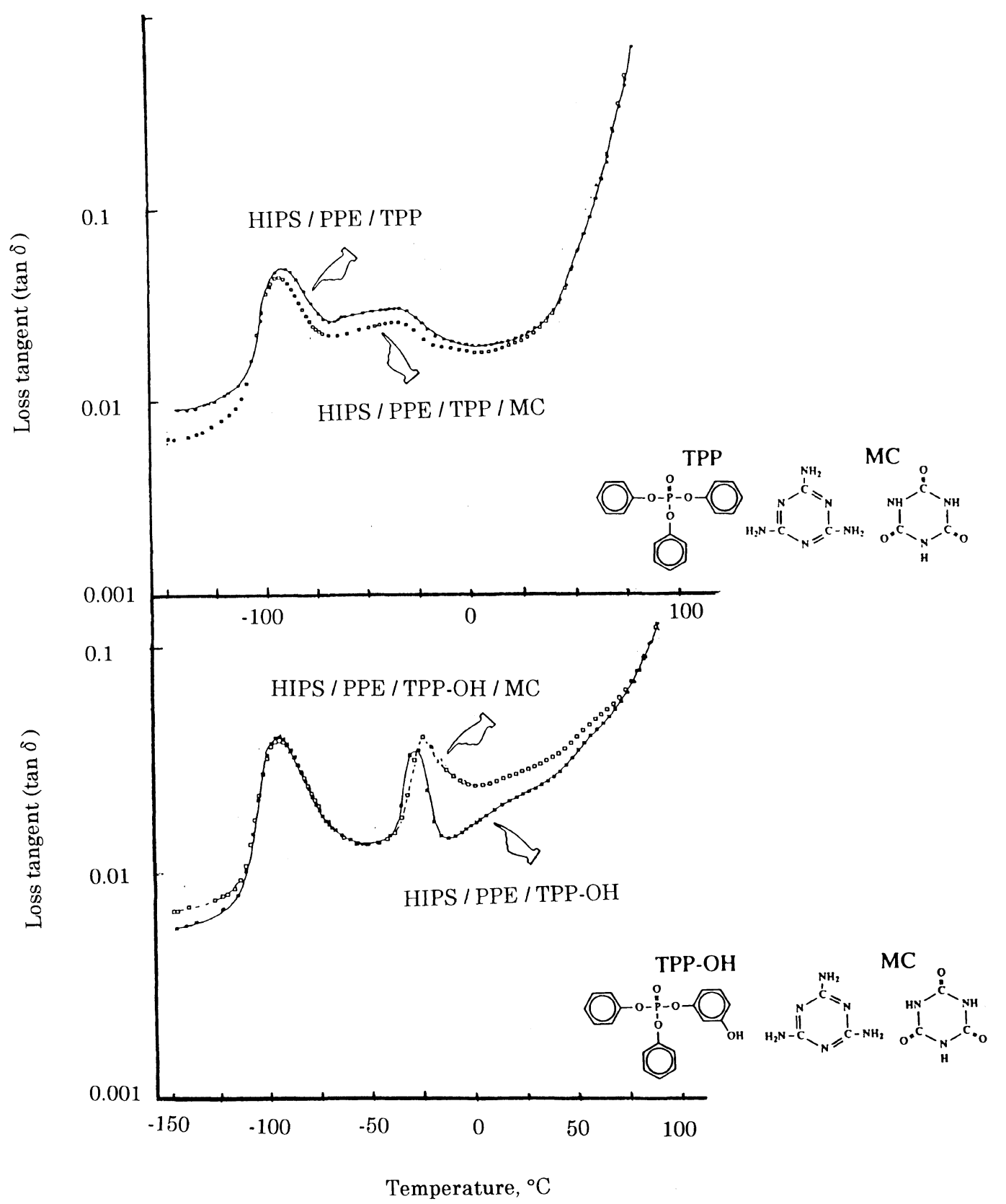

Figure 1. Effect of phosphate/MC interaction on viscoelastic behavior of HIPS/PPE resin.

Flame Retardance and Interaction between Flame Retardants

As shown in Table I, MC enhances flame retardance, regardless of the used phosphate, whether TPP-OH or TPP.

The effect of flame retardation assistance by triazine skeleton-containing compounds such as MC may be attributed to two mechanisms. In one, the simultaneous addition of a phosphate and a triazine skeletoncontaining compound leads to formation of phosphoramide, which shows a higher phosphorylating efficiency than phosphoric or polyphosphoric acids. ${ }^{9}$

The other is an intumescent fire retardance process, which involves the formation of char that swells and foams to produce a thermally insulative barrier with continued combustion. ${ }^{10}$ This layer of char is created by interactions among the three compounds in which PPE serves as a "carbonific", phosphate as a "catalyst", and
MC as a "spumific".

Figure 3 shows SEM photographs of the burned surface of specimens prepared from HIPS/PPE/TPP_OH compositions with and without MC. The many pores in the specimen obtained from the MC-containing composition suggest insulative foam barrier.

Figure 4 shows specimen burning surface temperatures, as measured by thermocouple, for the same resin compositions as in Figure 3, with and without MC. The intumescent process thus occurs upon the burning of this MC-containing resin composition and lowers the burning surface temperature by $130^{\circ} \mathrm{C}$ as compared with the resin composition without $\mathrm{MC}$, in which the intumescent process does not occur.

Table II shows the burning behavior of the specimens made from the resin compositions, and Figure 5 illustrates heat release rates. The presence of $\mathrm{MC}$ promotes char formation, and lowers the burning surface 


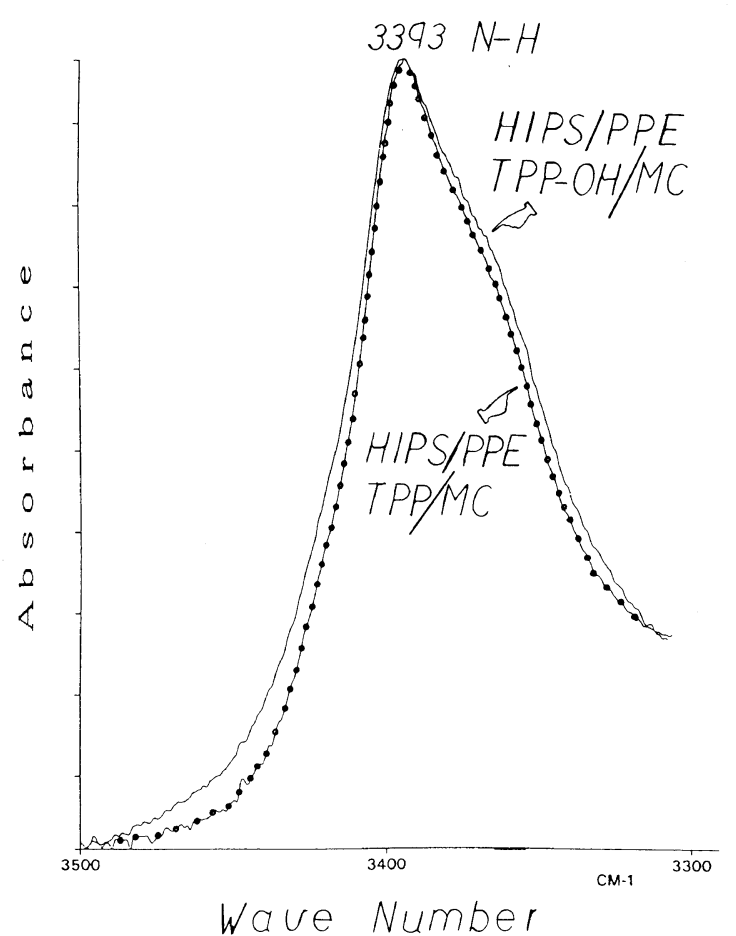

Figure 2. Effects of phosphate/MC interactions on FT-IR spectroscopy of HIPS/PPE resin.

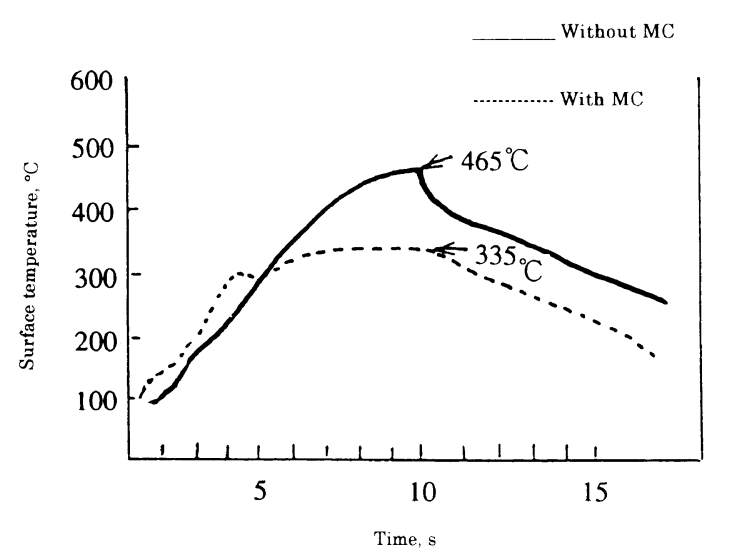

Figure 4. Burning surface temperatures of specimens (HIPS/TPP $\mathrm{OH}$ with and without MC), as measured by thermocouple.
HIPS/PPE/TPP-OH

Without MC $465^{\circ} \mathrm{C}$



HIPS/PPE/TPP-OH

With MC

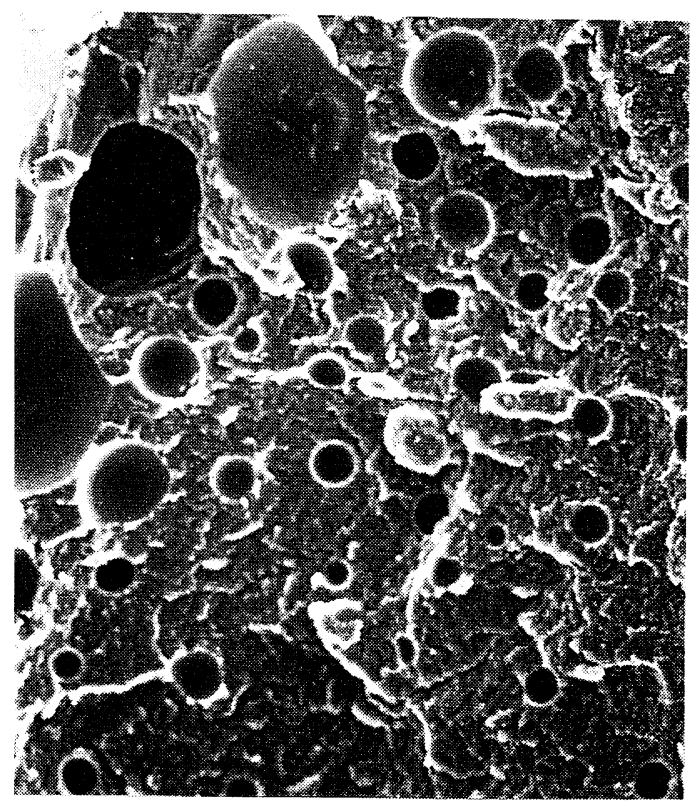

$150 \mu \mathrm{m}$

Figure 3. SEM photographs of burned specimen surfaces. 
Table II. Effects of MC on specimen burning behavior



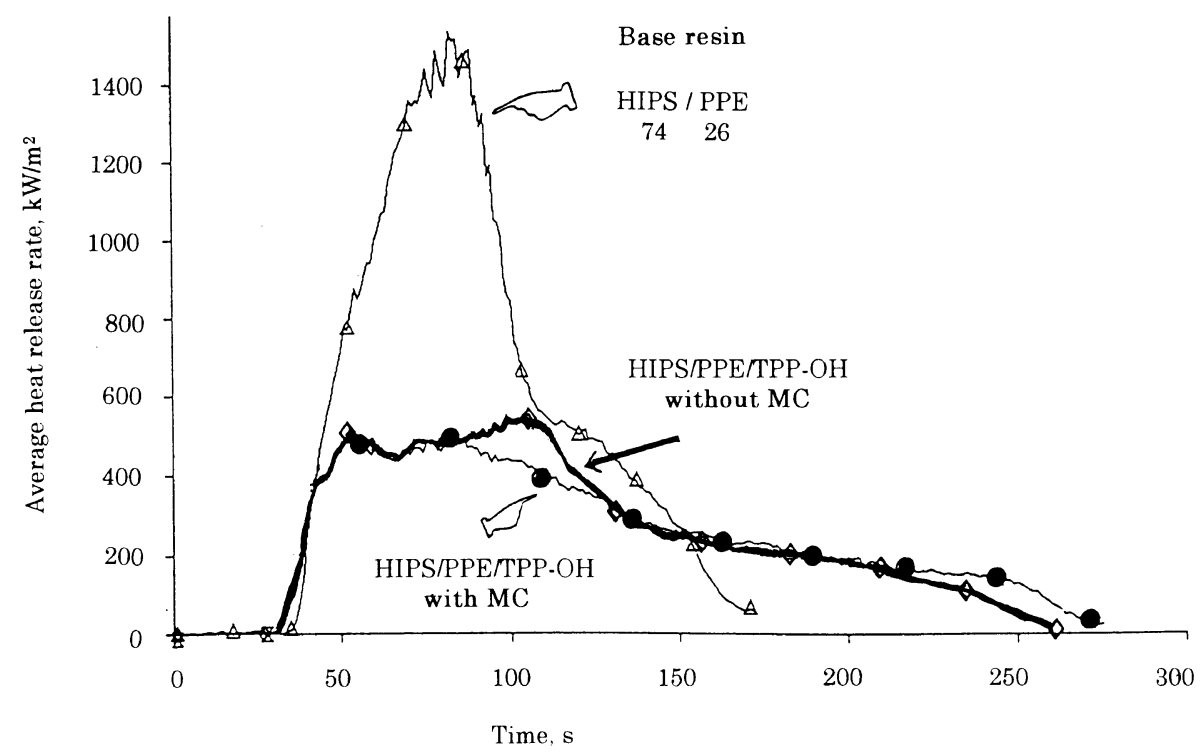

Figure 5. Effects of MC on average heat release rate.

temperature and heat release rate. ${ }^{11}$

The results of this study, show that hydrogen-bonding and intumescence-promoting interactions occur between TPP $-\mathrm{OH}$ and MC in flame-retardant HIPS/PPE formulations, thus making possible a halogen-free, flameretardant polystyrene possessing outstandingly high flame retardance (UL-94 V-0) with excellent flowability, heat resistance, and impact resistance.

\section{REFERENCES}

1. H. Nishihara, US Patent 5278212 (1994).

2. H. Nishihara, The 3rd ABC Kenkyu Toronkai (symposium), The Society of Polymer Science, Japan, 1994, pp 37-38.

3. H. Nishihara, Styrenics '96; MAACK Business Services, Plastics
Technology and Marketing 3rd Annual World Congress, Session I/2-1, Zurich, June, 1996.

4. H. Nishirara, "Fine Chemicals", Vol. 25, CMC Co., Ltd., Tokyo, 1996, No. 1, pp 41-53.

5. H. Nishihara, FRCA (Fire Retardant Chemicals Association) International Conference Report, Florida, 1995, pp 79-96.

6. H. Nishihara, Polym. Prepr., Jpn., 44, 555 (1995); English Edition, 44, E175 (1995).

7. H. Nishihara, "The Technology and Application of Polymeric Materials-Market and Outlook," CMC Co., Ltd., Tokyo, 1996, pp 432-481.

8. H. Nishihara, "The Plastics-Gosei Jushi," Vol. 42, The Japan Society of Plastics Technology, 1996, Ed., No. 11, pp 45-54.

9. G. Camino and L. Costa, Polym. Degrad. Stab., 20, 271 (1988).

10. H. L. Vandersall, J. Fire \& Flammability, 2, 97 (1971).

11. H. Nishihara, The 4th ABC Kenkyu Toronkai (symposium), The Society of Polymer Science, Japan, 1995, pp 51-52. 